Research Article

\title{
Research on the Involvement of Computer Graphics Algorithms in Systems for the Creation of Public Sculpture
}

\author{
Acheng Zhou (iD) and Chao Gao \\ School of Design, Jiangnan University, Wuxi 214122, Jiangsu, China \\ Correspondence should be addressed to Chao Gao; 1810012022@stu.jci.edu.cn
}

Received 14 September 2021; Accepted 9 October 2021; Published 21 October 2021

Academic Editor: Punit Gupta

Copyright (c) 2021 Acheng Zhou and Chao Gao. This is an open access article distributed under the Creative Commons Attribution License, which permits unrestricted use, distribution, and reproduction in any medium, provided the original work is properly cited.

\begin{abstract}
Currently, there is less research on how to improve the efficiency of the application of computer graphics technology in the creation of public sculpture. Therefore, this paper will focus on how computer graphics algorithms can enable systems for the creation of public sculpture with the intervention of computer graphics technology to create more accurate and completed works of public sculpture. It will explore and analyze how computer image algorithms can help creators apply computer image technology to finish complete and accurate public sculptures, and individual studies, computer imagery, and model analysis are also used. In systems for the creation of public sculpture, the point cloud data of the model is obtained through 3D laser scanning technology; then the algorithm of the point cloud model is integrated and the Statistical Outlier Removal algorithm of the point cloud model intervention is processed. By this way, the point cloud model of the work is optimized, and then a more completed and accurate public sculpture work can be produced by $3 \mathrm{D}$ sculpting or 3D printing. The research shows that, in the creation of public sculptures with the intervention of computer graphics technology, the computer graphics algorithm acquires the basis of the high-definition public sculpture data model. The computer graphics algorithm improves the accuracy and completeness of the creator using computer graphics technology; it is also the key to transform the accurate enlargement and transformation of the sculptural model into the actual sculptural work.
\end{abstract}

\section{Introduction}

Up to now, specialized computer graphics techniques and tools for the creation of public sculpture, such as ZBrush, Mudbox, 3D-Coat, 3ds Max, Blender, and Maya, have become common means of creation for many artists because those techniques and tools can broaden the creative approach of creators [1]. In the planning, designing, implementation, displaying, and dissemination of public sculpture, especially in the process of creating public proper sculpture, computer graphics technology is playing a big and important role in the development of public sculpture [2]. Along with the development of computer graphics technology, computer graphics technologies such as 3D scanning, 3D printing, and $3 \mathrm{D}$ sculpting, as well as related materials and equipment, have emerged one after another.
These techniques, materials, and equipment have been gradually involved in the creation of public sculpture and have great potential prospects for application. At the same time, some scholars in China have also begun to pay attention to this, for example, Liao Anshun's thesis on "The Use of Computer Image Technology in Public Sculpture Design" [3], Zhang Wang's thesis on "The Application of Computer Image Technology in Modern Public Sculpture" [4], and Zheng Miao and Deng Wei's thesis on "A New Approach to Plastic Art-Talking about Digital Technology Intervention in Sculpture" [5]; all the mentioned scholars and their papers have discussed this issue from different perspectives. The paper titled "A New Approach to Plastic Art-Talking about Digital Technology Intervention in Sculpture Art" by Zheng Miao and Deng Wei explores this issue from different perspectives. However, little research has been conducted on 
how to improve the integrity and accuracy of public sculptures created by creators using computer graphics technology.

In order to investigate how to make the public sculptures created by the public sculpture creation system with the intervention of computer graphics technology more accurate and complete, this paper will introduce some practical examples of public sculpture and analysis of relevant computer graphics algorithm formulas and models. Two questions will be mainly discussed in this paper: (1) What are the key points of computer graphics algorithms in systems for creation of public sculpture? (2) Which computer graphics algorithms and how can they be used to improve the accuracy and integrity of public sculptures created by computer graphics technology? These questions are explored in two separate sections: firstly, an analysis of the pathway for computer graphics algorithms to intervene in the creation of public sculpture and, secondly, an analysis of the specific ways in which computer graphics algorithms can intervene in the creation of public sculpture.

\section{Pathways for the Intervention of Computer Graphics Algorithms in Systems for Creation of Public Sculpture}

Computer image algorithms are the software systems that make computer image technology possible, and, in this perspective, computer image algorithms are also called digital image processing algorithms. The involvement of computer graphics algorithms in the creation of public sculpture is achieved through computer graphics technology. Therefore, a study of the path of computer graphics algorithms in systems for creation of public sculpture also needs to start with the way in which computer graphics technology intervenes in public sculpture creation systems.

Systems for creation of public sculpture are formed on the basis of urban master plans and therefore they do not have a fixed pattern [6]. In order to clearly understand the involvement of computer graphics algorithms in the creation of public sculpture, we can start by analyzing the involvement of computer graphics technology in the creation of public sculpture. On this basis, we can then explore the involvement of computer graphics technology in the creation of public sculpture itself, and, by this, the key points of the involvement of computer graphics algorithms in the creation of public sculpture can be clearly clarified.

\subsection{Intervention in Public Sculpture Creation Process System} through Computer Graphics Technology. In terms of the process of creating public sculpture, the system of creating public sculpture can be understood as follows: planning of public sculpture-creation of design-production of works-installation of works-display and dissemination. This creation system is the procedure for the creation of public sculpture and can therefore also be called the public sculpture creation process system. However, the steps in the public sculpture creation process system are not linear but have nonlinear characteristics. The path of computer graphics algorithms in the creation of public sculpture can be analyzed through the model of a public sculpture creation process system involving computer technology.

In order to help the creator to complete the creation of the public sculpture, different computer graphics technologies can be involved in each stage of the public sculpture creation process. In the planning stage of public sculpture, software and technologies such as planimetric mapping, 3D mapping, spatial analysis, and virtual reality can be involved; in the design stage, software and technologies such as $2 \mathrm{D}$ design, 3D modelling, and 3D scanning software can be involved; in the production stage, technologies and tools such as $3 \mathrm{D}$ printing, numerical control, and digital materials can be involved; in the installation stage, software and technologies such as planimetric mapping and 3D mapping can be involved; and, in the display and dissemination stage, software and technologies such as numerical control and multimedia can be involved. Software and technology can be involved in the installation stage of the work; in the display and dissemination stage, technology such as CNC, multimedia, and Internet technology can be involved.

In the process of creating public sculpture, computer graphics technology will also intervene in systems for creation of public sculpture as a means of artistic expression for the creator. Its intervention in the creation system of public sculpture is mainly manifested in two ways, namely, the method of using digital technology as a starting point and the method of using public sculpture as a starting point. The specific expressions are as follows: (i) the use of digital technology means related to information expressions such as lighting, sound, and three-dimensional images [7] and (ii) the use of traditional public sculpture languages such as materials, shapes, and contexts [8]. In general, the traditional language of public sculpture is the inner shell and the digital technology is the outer one, and both work together to make computer graphics technology reasonably effective in the creation of public sculpture.

In order to introduce computer graphics technology into the creation of public sculpture in a natural, dynamic, and scientific way, its involvement in the creation of public sculpture needs to be carried out under certain conditions and bases. [9] In other words, there are certain principles that need to be followed when computer graphics technology is introduced into the creation of public sculpture. Firstly, the basic characteristics of public sculpture must be followed and the concept of art for the public must be upheld [10]. Secondly, the public should be the main subject, and the relationship between the public, public sculpture, and public space should be well coordinated [11]. It is also necessary to follow the characteristics of digital technology and to grasp the intrinsic links between the various factors involved in the creation of public sculpture, so that it can give full play to creativity in the system [12]. In addition, the systemic and creative nature of the creation of public sculpture must be followed [13]. This means that the basic characteristics of public sculpture, the principle of the trinity of public, public sculpture, and public space, the characteristics of digital technology itself, and the principles of systemic and creative creation must be followed. 
In other words, when computer graphics technology is intervened in public sculpture creation program system, the functions and themes to be achieved have to be considered, certain principles have to be obeyed, and relevant methods have to be used, so that all parts of the public sculpture creation process can be complementary, interrelated, and integrated into one [14]. The integration of computer graphics technology into the process of creating public sculpture allows for a high degree of integration between digital technology and the creation of public sculpture, optimizing the process of creation and greatly reducing the time and cost of production, as well as ensuring the accuracy, ease of installation, and safety of use of the work. In short, the involvement of computer graphics technology in the creation of public sculptures can make the creation of public sculptures more rational, systematic, and effective. A model of a public sculpture creation process involving computer graphics technology is shown in Figure 1.

The computer graphics algorithm, in short, is a computer graphics technology that intervenes in the "planningcreation-design - installation-display and dissemination" of public sculpture according to the functions and themes to be achieved, following certain principles and using relevant methods. The process of creating a public sculpture is based on the principles of planning-creating-designing_installing-displaying, and disseminating, and thus, it helps the creator to complete the public sculpture.

\subsection{Intervention in the Ontological System of Public Sculpture} Creation through Computer Graphics Technology. The creation process system of public sculpture contains a number of unit links, which can be regarded subsystems of the creation process system [15]. The process of creation, design, production, and installation is the process of creating the body of public sculpture, which can be called the ontological creation system of public sculpture. This ontological system of public sculpture creation determines the way in which public sculpture artworks exist, and its system composition has a close relationship with public space and audiences [16]. Therefore, it can be said that the ontological system of public sculpture creation is the core of the public sculpture creation process system. The effect of the intervention of computer graphics technology in the ontological system of public sculpture creation has a decisive impact on the quality of public sculpture.

The involvement of computer graphics technology in the creation of public sculpture is also based on the functions and themes to be achieved and on certain principles and methods. In addition, it is important to adhere to the concept of creation and to apply computer graphics technology on the base of the way in which the art exists. Besides, the significance and value of computer graphics technology in the creation of public sculpture should be considered. Moreover, it is necessary to analyze and study what kind of computer graphics technology should be involved, in what way, and in which system and link the concept and positioning of the creation to the various units of the system of ontological creation, so as to play the proper role of the system together [17]. For example, the Chinese artist Dong Shubing created the public sculpture "Son of the Earth" firstly acquiring the data model through $3 \mathrm{D}$ scanning of the sleeping baby and then enlarging the whole model to 15 metres long and dividing it into $40 \mathrm{~cm}$ square units, followed by sculpting the red sandstone material into solid units according to the content and size of the units through $3 \mathrm{D}$ sculpting technology and finally putting the units together. The solid units are then assembled and placed in a monumental size on the Gobi beach, conveying the idea of a sleeping child of the Earth lying in the arms of the sky and the Earth. The author has carried his concept through to the positioning of the infant figure and the ontology creation system through a series of steps such as $3 \mathrm{D}$ scanning to obtain the data model-analysis and refinement of the $3 \mathrm{D}$ data model-division of the 3D data model-sculpting of the divided data model units-installation of the work in a series of ontological creation systems (as shown in Figure 2). Throughout the creation system of this work, computer graphics technology strongly supports the author's creating process, creative ideas, and the realization of the artistic presence of the public sculpture [18].

Of course, the main way in which computer graphics technology is currently being used for creation is to combine it with manual creation. This, then, requires full consideration of the integration of digital technology with the manual shaping process. In the ontological creation of such public sculptures, the creation of small sculptural drafts is usually done manually, and then the small drafts are scanned through 3D scanning technology and tools; then the scanned data is processed and enlarged, and, next, the public sculptures are printed using 3D printing technology and tools and finally modified and refined by hand. For example, Chinese artist Sui Jianguo's public sculptures in the Handwriting series were created using a combination of $3 \mathrm{D}$ scanning and $3 \mathrm{D}$ printing technology. The sculptural forms of clay or plaster made by hand are scanned by the author using 3D scanning technology and then enlarged in a computer to show clearly the texture of the hand that remains in it, and then the enlarged forms are printed out in fine detail using 3D printing technology, and finally the work is finished by turning and installing (as shown in Figure 3). Through 3D scanning technology and 3D printing, presenting the creator's manuscript in a clear and complete enlargement becomes a quite possibility. Besides this, new connotation and meaning of the product are displayed.

In this type of ontology system, 3D scanning and $3 \mathrm{D}$ printing technologies allow the creator to have more space and possibilities for artistic expression. In this type of public sculpture, the accuracy of 3D scanning and 3D printing technology has a crucial impact on the degree of completion of the public sculpture [19]. Improving the accuracy of 3D scanning and 3D printing technologies and tools is therefore key to their efficient involvement in the creation of public sculptures.

In the process of creating a system of public sculpture with the involvement of computer graphics technology, 3D scanning is the process of acquiring model data and $3 \mathrm{D}$ 


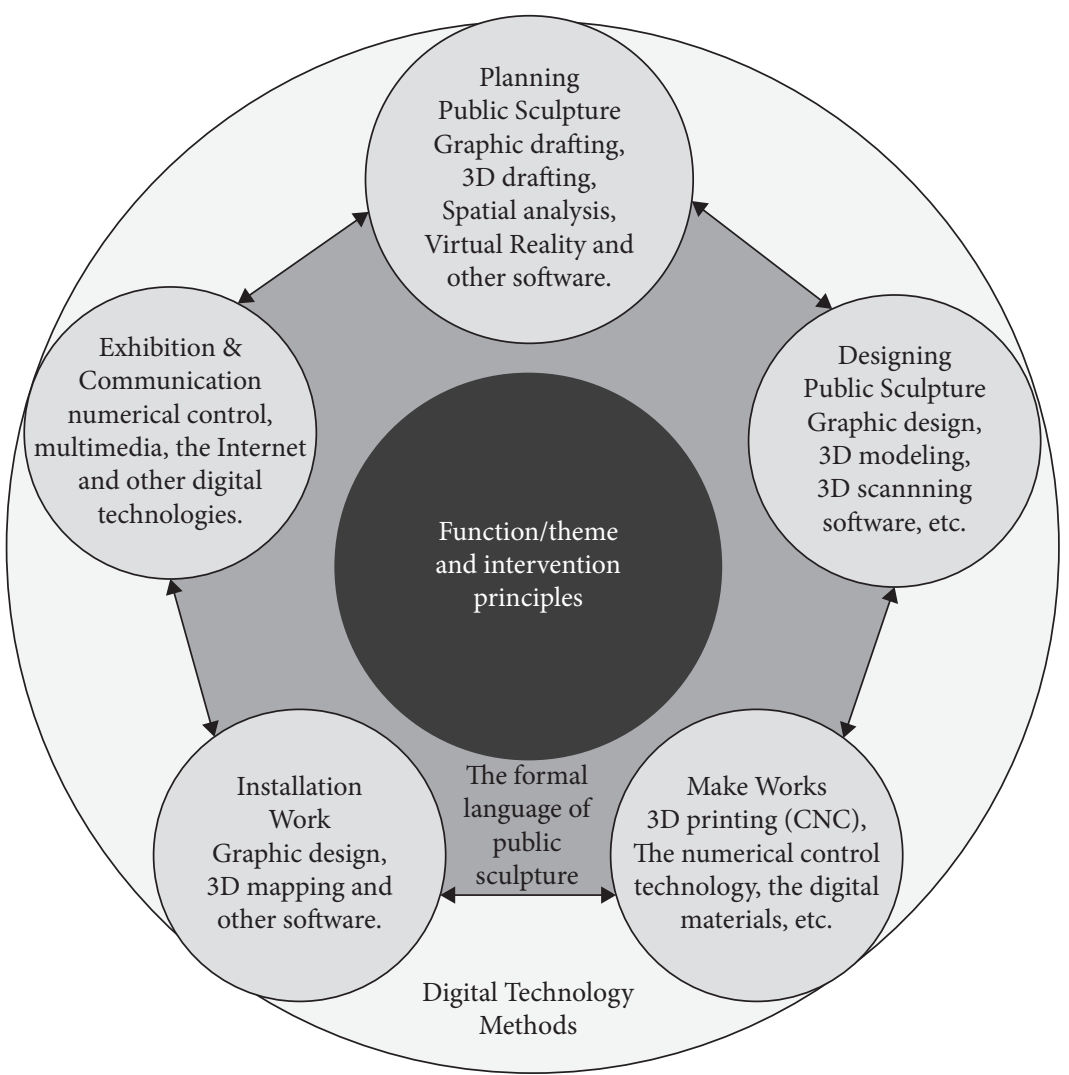

Intervention principles:

1)Following the basic characteristics of public sculpture art;

2)Following the principle of trinity of public, public sculpture and public space; 3)Following the characteristics of Computer imaging technology itself; 4)Following the systematic and creative nature of creation;

Intervention methods:

1)lighting, sound and the use of digital technical means of expression such as three-dimensional images.

2)The use of public sculpture language such as material,shape and context.

FIgURE 1: A model of a public sculpture creation system with the intervention of computer graphics technology.
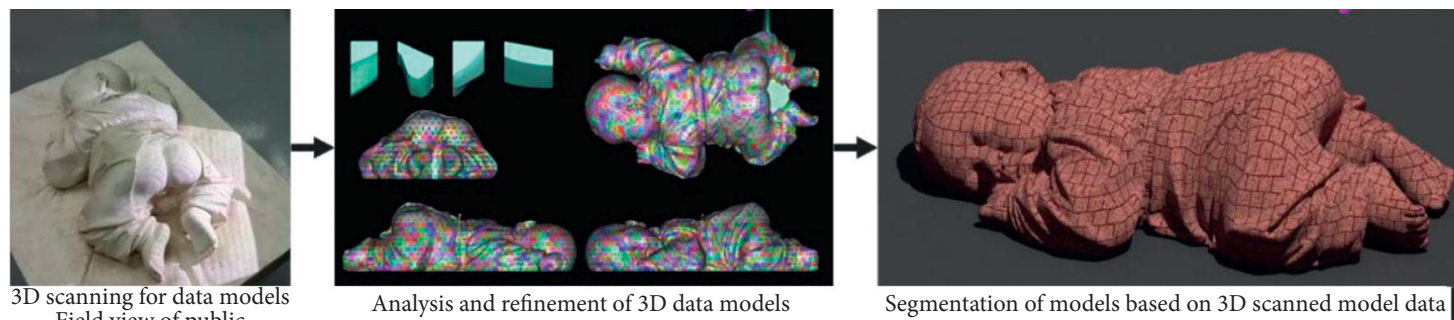

Field view of public sculpture works

Segmentation of models based on 3D scanned model data
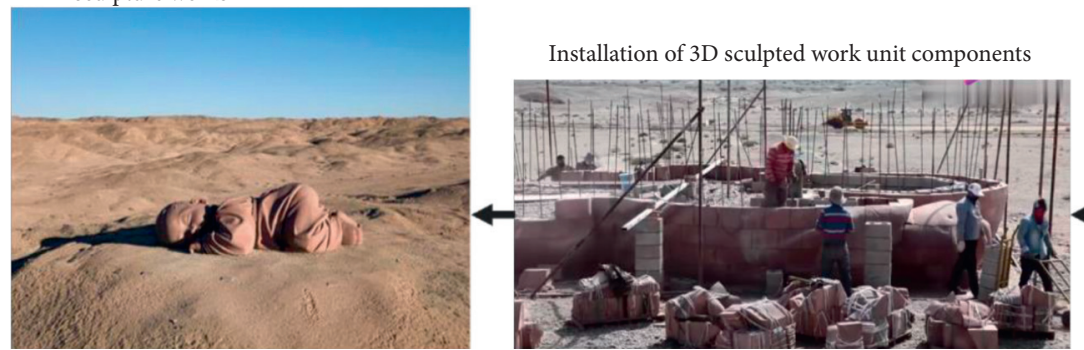

3D sculpting based on segmented model data

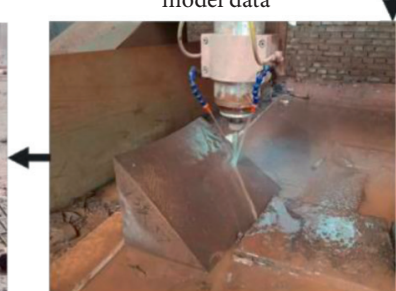

FIGURE 2: Intervention of computer graphics technology in the ontological system process of the creation of Children of the Earth.

printing or sculpting is the process of outputting the data [20]. The key to improving the accuracy of $3 \mathrm{D}$ printing or $3 \mathrm{D}$ sculpting techniques and tools lies in the process of improving the accuracy of the data model acquiring and outputting. In the process of acquiring data model and outputting it, with certain amount of 3D scanning equipment, the key to improving the accuracy of the acquired data lies in the processing of the acquired with a certain amount of 3D scanning equipment, and the key to improving the accuracy of the acquired data model lies in the processing of the acquired data model. That is to say, in the case of certain amount of 3D scanning equipment, after 3D scanning of the work model, the acquired $3 \mathrm{D}$ model data also needs to be processed to make the $3 \mathrm{D}$ data more accurate and complete, and then accurate and complete works can be produced through $3 \mathrm{D}$ printing technology. From this point of view, in the process of creating public sculptures with the involvement of computer graphics technology, the integrity and 


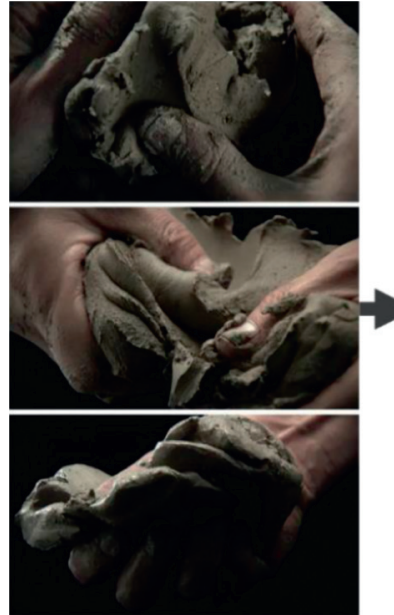

Some forms of the hand pinch
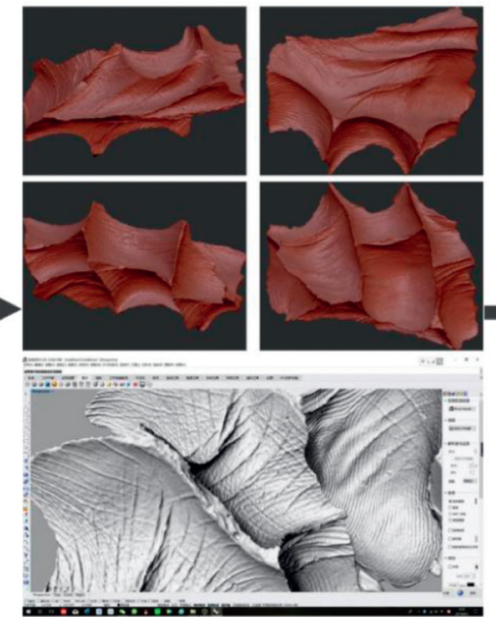

Processing of data collecting by $3 \mathrm{D}$ scanning

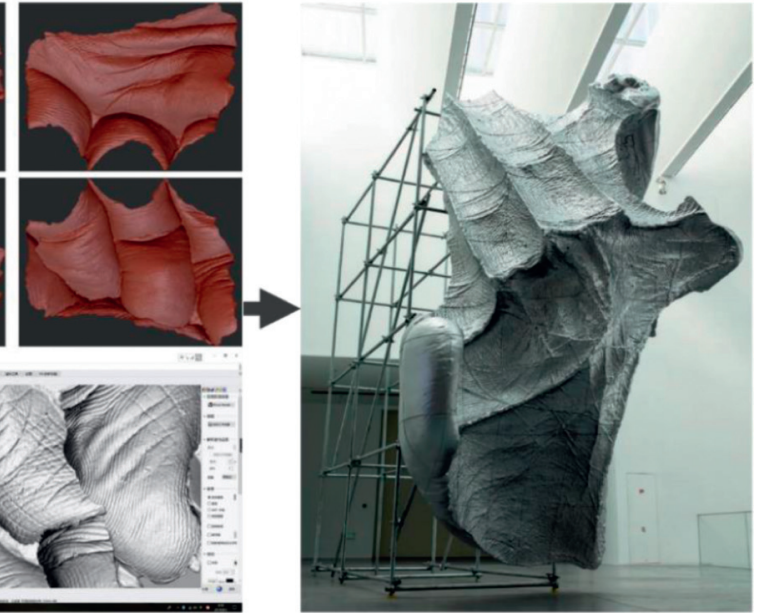

A 3D-printed sculpture

Figure 3: Computer graphics intervention in the making of the sculpture "Handwriting."

accuracy of the work depend on the collection and processing of the data of the public sculpture [21]. This requires the intervention of computer graphics algorithms, which are thus involved in the creation of public sculpture systems to help creators use computer graphics technology to create complete and accurate public sculptures. In short, the key to improving the accuracy of 3D scanning and $3 \mathrm{D}$ printing technologies and tools is the intervention of computer graphics algorithms.

\section{Intervention Methods of Computer Graphics Algorithms in Systems for Creation of Public Sculpture}

In systems for creation of public sculpture, since the intervention of computer graphics algorithm is the key to the creator's ability to create accurate and complete public sculptures through computer graphics technology, what kinds of computer graphics algorithms are used? How can they be used to help the creator to create accurate works? These questions are addressed in the following discussions: the computer graphics algorithms and their interventions in the collection, processing, and output of data from the model objects of public sculpture.

3.1. Collecting Data of Public Sculptural Works. In the practice of creating public sculptures, 3D laser scanning, also known as point cloud scanning, is the most common 3D scanning technique used to obtain data models of works. This technology is currently more mature and has a very high accuracy, for example, the 3D CaMega body scanner from Beijing Bovee Hengxin, with a measurement accuracy of $0.50 \mathrm{~mm}$. Using 3D laser scanning technology based on harmless white light to scan the whole body, this scanner can obtain accurate 3D data of the human as quickly as several seconds [22].

Point cloud scanning technology incorporates photonics, computer graphics, and information processing and computer vision technologies. The principle is to obtain the spatial coordinate data of the object surface by scanning the spatial shape and structure of the object [23]. In order to obtain a point cloud model data of the object, the point cloud scanning technique takes a noncontact approach, scanning the spatial shape and structure of the object to obtain the spatial coordinates of the surface.

The 3D point cloud data model is formed using geometric data of the surface of the object obtained by scanning the target object using the 3D scanning tool, which has a customized 3D coordinate system (see Figure 4) consisting of three mutually perpendicular $X$-, $Y$-, and $Z$-axes, capable of indicating the point cloud coordinate data of the object. When the $3 \mathrm{D}$ point cloud scanner is used to acquire the point cloud data, a laser emitter sends a laser pulse to the target object, which is then diffusely reflected on the surface of the target object and the laser signal returns in an almost identical path, which is then received by the built-in receiver of the instrument, and then this instrument calculates the distance between the target point and the scanner. At the same time, the scanner detects and counts the transverse angular value $\alpha$ and the longitudinal angular value $\theta$ of the pulse signal [24]. From this, the point cloud coordinates of the target object can be calculated according to equation (1), which enables the point cloud coordinates to be calculated, thus obtaining the point cloud data of the object.

$$
\left\{\begin{array}{l}
X_{P}=S \cos \theta \cos a, \\
Y_{P}=S \cos \theta \sin a, \\
Z_{P}=S \sin \theta .
\end{array}\right.
$$

During the period of creating a public sculpture, the creator can use the $3 \mathrm{D}$ point cloud scanner to scan the model of the public sculpture or the solid object without contact and therefore without damage to the scanned object. Once the scanning of the model or solid object is completed, the point cloud data of the model or solid object can be obtained with the intervention of the cloud point $3 \mathrm{D}$ coordinate formula. For example, when the Chinese artist Dong 


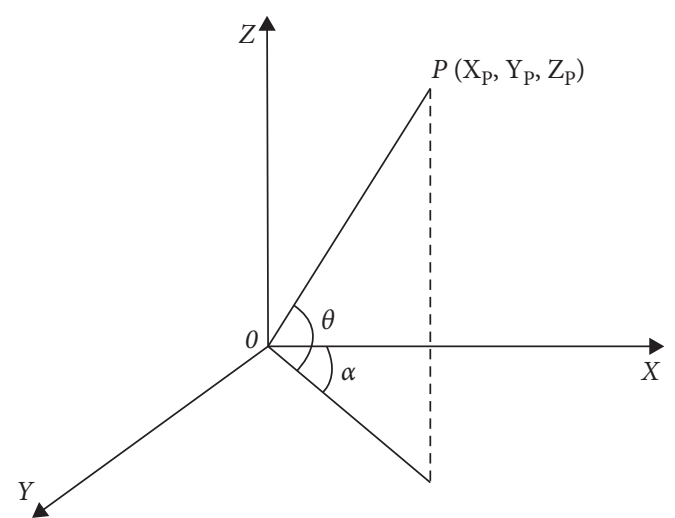

FIgURE 4: Diagram of the coordinate system in the 3D scanning tool.

Shubing created the work "Children of the Earth," he used this scanning technique to scan a baby to obtain data of the model object; when the Chinese artist Sui Jianguo created the series "Handwriting," he used this scanning technique to scan a hand-crafted clay model to obtain data of the model object.

\subsection{Processing of Data Models for Public Sculpture Works.} In the creation of public sculpture, the quality of the point cloud model directly determines the accuracy and completeness of the public sculpture produced by $3 \mathrm{D}$ printing technology [25]. However, public sculptures are often complex, and it is difficult to obtain accurate and complete point cloud data from just one perspective. Therefore, in order to collect more accurate and complete point cloud data models, it is often necessary to use a multiangle scanning approach to obtain data of public sculptures in multiple directions. This then requires the processing of the collected point cloud data models in multiple orientations. The processing of the collected point cloud data models is an essential part of improving the quality of the point cloud models. The processing of the collected point cloud data models consists of two steps: integration of the point cloud data models and noise reduction of the point cloud data models.

3.2.1. Integration of Point Cloud Data Model. The point cloud data models of public sculptures obtained from different angles by $3 \mathrm{D}$ scanning equipment need to be integrated to form a complete point cloud model. This requires the point cloud data models from different angles to be converted into the same coordinate system, a process known as integration of point cloud data models [26].

When the same 3D scanning device is used to scan a model object of a public sculpture, the point cloud data models obtained from different angles have the same proportional relationship to each other and can be converted to a uniform coordinate system by simply translating or rotating the different point cloud data models when integrating them. That is to say, if the coordinates of the first set of point cloud data models $\left(x_{1}, y_{1}, z_{1}\right)$ are transformed into the coordinates of the second set of point cloud data models $\left(x_{2}, y_{2}, z_{2}\right)$, only three rotation parameters $(\alpha, \beta, \gamma)$ and three translation parameters $(\Lambda x, \Lambda y, \Lambda z)$ need to be transformed. Of course, if these six parameters are to be calculated, more than three points are required to be common to the different point cloud data models. The algorithm for the conversion of point cloud data model coordinates is given in equations (2) and (3) [27].

$$
\left[\begin{array}{l}
X \\
Y \\
Z
\end{array}\right]=R(a, \beta, \gamma)\left[\begin{array}{l}
x \\
y \\
z
\end{array}\right]+\left[\begin{array}{c}
\Lambda x \\
\Lambda y \\
\Lambda z
\end{array}\right]
$$

From equation (2),

$$
R=\left[\begin{array}{ccc}
\cos \beta \cos \gamma & \cos \beta \sin \gamma & -\sin \beta \\
-\cos \alpha \sin \gamma+\sin \alpha \sin \beta \cos \gamma & \cos \alpha \cos \gamma+\sin \alpha \sin \beta \sin \gamma & \sin \alpha \cos \beta \\
\sin \alpha \sin \gamma+\cos \alpha \sin \beta \cos \gamma & -\sin \alpha \cos \gamma+\cos \alpha \sin \beta \sin \gamma & \cos \alpha \cos \beta
\end{array}\right] .
$$

There are two ways to integrate point cloud data model: the first way is feature-point-based integration and the second is non-feature-point-based integration [28]. The feature-pointbased integration approach is to identify more obvious feature points between each point cloud data model to be integrated and then to integrate the coordinate parameters of these feature points to complete the integration of the point cloud data model. In public sculpture creation systems, the feature-pointbased integration approach is more suitable for integrating the point cloud data models of public sculpture objects, because public sculptures usually have unique modelling characteristics.
The integration process based on feature points is as follows [29]:

(1) Find the feature points $p_{1}, p_{2}, p_{3}$ of the first set of point cloud data model and the corresponding feature points $b_{1}, b_{2}, b_{3}$ of the second set of point cloud data model.

(2) As the following vector: $\left(p_{1}-p_{2}\right),\left(p_{3}-p_{1}\right)$, $\left(b_{2}-b_{1}\right), \quad\left(b_{3}-b_{1}\right), \quad$ order $\quad N_{1}=p_{2}-p_{1} \quad$ and $M_{1}=b_{2}-b_{1}$.

(3) As the following vector: $U_{3}$ and $M_{3}$. 


$$
\left\{\begin{array}{l}
U_{3}=U_{1} \times\left(p_{3}-p_{1}\right), \\
M_{3}=M_{1} \times\left(b_{3}-b_{1}\right) .
\end{array}\right.
$$

(4) As the following vector: $N_{2}$ and $M_{2}$.

$$
\left\{\begin{array}{l}
U_{2}=U_{3} \times U_{1}, \\
M_{2}=M_{3} \times M_{1} .
\end{array}\right.
$$

(5) As the following unit vector:

$$
\begin{aligned}
& u_{1}=\frac{u_{1}}{\left|u_{1}\right|}, \\
& u_{2}=\frac{u_{2}}{\left|u_{2}\right|}, \\
& u_{3}=\frac{u_{3}}{\left|u_{3}\right|} . \\
& m_{1}=\frac{M_{1}}{\left|M_{1}\right|}, \\
& m_{2}=\frac{M_{2}}{\left|M_{2}\right|}, \\
& m_{3}=\frac{M_{3}}{\left|M_{3}\right|} .
\end{aligned}
$$

(6) Convert any point of $[n]$ to $[m]$ by the formula $P_{i}^{\prime}=P_{i} R+T$.

(7) Since $[m]=[u] R$, the rotation matrix $R=[u]^{-1}[m]$ can be solved for.

(8) Let $P_{1}^{\prime}=b_{1}$ and $P_{1}=p_{1}$, and bring them into the formula $P_{i}^{\prime}=P_{i} R+T$, then the translation matrix can be derived as follows:

$$
T=b_{1}-p_{1}[u]^{-1}[m] .
$$

(9) Based on the previous equations, the equation formula for integrating the point cloud data model for public sculptures can be rewritten as follows:

$$
A^{\prime}=A[u]^{-1}[m]-A_{1}[u]^{-1}[m]+b_{1} \text {. }
$$

Based on the above steps, the integration of different point cloud data models of the same public sculpture model object can be achieved with the intervention of the computer graphics algorithm formula; all these can make the point cloud model obtained by scanning the public sculpture model or solid object with the 3D scanning tool more accurate and complete.

3.2.2. Noise Reduction Processing by Point Cloud Model. When acquiring point cloud data models of public sculptures or solid objects through 3D scanning, the acquired point cloud data models may produce some noise in the point cloud data models due to the influence of the instruments or the working environment. In systems for creation of public sculpture, these noises in the point cloud model will have a negative impact on the main body of the point cloud model, which in turn will affect the quality of the public sculpture produced by the $3 \mathrm{D}$ printing technology. Therefore, in order to obtain a clearer and more detailed 3D model, the point cloud data model needs to be integrated and then noise-reduced.

Some noise can be easily noted, and it can be dealt with manually, while less obvious noise needs to be dealt with in an appropriate way. For the creation of public sculptures, the Statistical Outlier Removal method is more effective in dealing with noise in point cloud data models [30].

The Statistical Outlier Removal method was used to deal with the noise in the point cloud data model as follows [31]:

(1) Set the noise reduction region $D$ of the point cloud model, where the number of point clouds is $n$. Starting from point $P_{i}$, the distance from $P_{i}$ to all its neighbouring points is $d_{i}$; then, according to equation (9), the average distance $\delta$ and standard deviation $\sigma_{i}$ can be solved.

$$
\begin{aligned}
\mu & =\frac{\sum_{i-1}^{n} d_{i}}{n}, \\
\sigma^{2} & =\frac{\sum_{i-1}^{n}\left(d_{i}-\mu\right)^{2}}{n-1} .
\end{aligned}
$$

(2) Since the number of point clouds is $n$ and the previous step needs to be repeated to obtain $N$ that means the number of average distances and standard deviations, equation (10) can be used to calculate the average distance $\mu_{o}$ and standard deviation $\sigma_{o}$ from the noise points to point $P_{i}$ in the whole point cloud data model.

$$
\begin{aligned}
\mu_{o} & =\frac{\sum_{i-1}^{n} \mu_{i}}{N}, \\
\sigma_{o}^{2} & =\frac{\sum_{i-1}^{n}\left(\mu_{i}-\mu_{o}\right)^{2}}{N-1} .
\end{aligned}
$$

(3) The average distance of all the noise points in the point cloud data model to point $P_{i}$ is judged, and the standard deviation multiplier is positioned at $k$. If the average distance value is greater than $\mu_{o}+k \sigma_{o}$, then the noise points can be judged to be deleted.

In systems for creation of public sculpture, the Statistical Outlier Removal method is used to process the noise in the point cloud data model, resulting in a clearer point cloud data model of the captured public sculpture work model or solid object.

3.3. Output of Data Model for Public Sculpture Works. The process of exporting the point cloud data model is in fact the process of applying $3 \mathrm{D}$ printing technology and equipment to produce public sculptures based on the collected and processed data models. In a public sculpture creation system, the point cloud model data of the public 
sculpture model or solid object is collected and processed by $3 \mathrm{D}$ scanning, and then the public sculpture is produced by $3 \mathrm{D}$ printing technology [32].

There are two main types of 3D printing technology used in systems for creation of public sculpture: The first type is CNC (Computer Numerical Control Machine) numerical control sculpting technology, also often called 3D sculpting technology, which renders works by subtracting material [33]. The second is the $3 \mathrm{D}$ shaping technology by adding materials to render the work, which is commonly referred to as $3 \mathrm{D}$ printing technology. In all of these, CNC sculpting technology is used to manipulate the robotic arm by digital control to carve materials such as foam, stone, and wood into sculptural objects [34]. CNC engraving technology is less accurate than 3D shaping technology, and therefore it is less used in the production of highly refined public sculptures. However, it is often used in the production of large public sculptures that require a low degree of refinement. For example, in Chinese artist Dong Shubing's public sculpture "Son of the Earth," the physical presentation of the point cloud data model of the model object is completed by CNC engraving technology. The $3 \mathrm{D}$ shaping technology is a technique of stacking resin, plastic, and powdered metal materials into three-dimensional objects by means of layerby-layer printing. In the process of creating public sculpture, 3D shaping technology can accurately restore the digital model collected and processed, enabling the digital model to be accurately converted into a public sculpture entity. For example, in the case of Chinese artist Sui Jianguo's public sculpture series "Handwriting," the point cloud data model of his work is physically shaped by 3D shaping technology.

In systems for creation of public sculpture involving computer graphics technology, the accuracy of the output of the point cloud data model of a public sculpture depends primarily on the obtaining and processing of the point cloud data model. In other words, the accuracy of the work is determined by the processing of the point cloud data model, whether it is achieved by subtracting material through $3 \mathrm{D}$ sculpting or adding material through 3D shaping. The effect of the processing of the point cloud data model lies in the intervention of appropriate computer graphics algorithms. The accuracy of public sculptures can be improved by the integration of feature-based algorithms and Statistical Outlier Removal algorithms into public sculpture creation systems.

\section{Conclusion}

Due to the paucity of relevant research, this paper draws on a limited number of sources and is therefore limited in the depth of what it can explore. The following conclusions can be drawn from an analysis of the ways and means by which computer graphics algorithms can intervene in the creation of public sculpture systems:

(1) The involvement of computer graphics algorithms in systems for creation of public sculpture is achieved through the involvement of computer graphics technology in the creation program system and the ontology system of public sculpture. The involvement of computer graphics algorithms in systems for creation of public sculpture is the key to the creation of accurate and complete public sculptures by the creator through computer graphics technology.

(2) The impact of computer graphics algorithms on public sculpture creation systems is mainly displayed in the process of extracting and processing the point cloud data model of a public sculpture, which is obtained by scanning with a 3D scanning tool and calculating the point cloud coordinate formula. In order to obtain a complete and clear point cloud data model of the public sculpture object, the point cloud data model conversion formula can be used to integrate the point cloud data models of different angles of the same object model, and then the Statistical Outlier Removal algorithm is used to process the noise in the point cloud data model.

(3) In the public sculpture creation system, the computer image algorithm is the basis for collecting, processing, and transforming the point cloud data of the public sculpture work with high definition. Its intervention in the public sculpture creation system improves the accuracy of the sculptor's using computer graphics technology when they create public sculptures. Besides, it plays a key role when the creator use computer graphics technology to accurately enlarge and transform public sculpture models into physical public sculptures.

\section{Data Availability}

Data sharing is not applicable to this article as no datasets were generated or analyzed during the current study.

\section{Conflicts of Interest}

The authors declare that they have no conflicts of interest.

\section{References}

[1] S. Zhu, "Opportunities of edges-prospect of sculpture under 5G," Sculptre, vol. 132, no. 4, pp. 22-26, 2019.

[2] W. He, "Public sculpture design strategy in the perspective of rural revitalization," Journal of Anshan Normal University, vol. 21, no. 6, pp. 78-81, 2019.

[3] A. S. Liao, "The use of computer imaging technology in the design of public sculpture," Ceramics Science \& Art, vol. 73, no. 6, pp. 18-22, 2020.

[4] W. Zhang, "A discussion of computer imaging technology and public sculptures," Architecture \& Culture, vol. 145, no. 10, pp. 21-23, 2015.

[5] M. Zheng, "A new approach to plastic art - digital technology intervention in public sculpture art," Fine Art, vol. 65, no. 4, pp. 75-77, 2017.

[6] J. Zhang, "A preliminary investigation of the content and methods of public art planning based on urban cultural construction," Art Journal, vol. 56, no. 5, pp. 103-108, 2018.

[7] W. Wang, "Research on digital media art under the characteristics of technicality," Stage, vol. 11, pp. 94-97, 2017. 
[8] W. Liao, "Narrative analysis of sculptural language," Qilu Realm of Arts, vol. 115, no. 4, pp. 15-17, 2010.

[9] Xi-C. Zhang, "Reflection on the principle of publicness of urban cultural space and sculpture," Creative Design Source, vol. 121, no. 5, pp. 4-11, 2017.

[10] C. Wang, "Analysis of modern urban public art issues," Urban Construction Theory Research, vol. 35, no. 5, pp. 1610-1611, 2015.

[11] G. Zhang, "The convergence of diversity: the new media turn in public art," Art and Design, vol. 1, pp. 176-180, 2017.

[12] Z. Guo, "Analysis of the application and maintenance of digital fiber optic communication equipment," Information/ Communication, vol. 189, no. 9, pp. 255-258, 2018.

[13] W. Zhang, "Research on the application of digital technology in modern public sculpture," Architecture \& Culture, vol. 115, no. 10 , pp. 21-25, 2015.

[14] W. Luo, "Urban sculpture based on 3D scanning and 3D printing technology," Art Panorama, vol. 102, no. 8, pp. 107-108, 2020.

[15] J. Chen and K. Leng, "Public Sulpture Manufacturing System Based on Virtual Reality and 3D Printing," Design, vol. 201, no. 15, pp. 26-27, 2015.

[16] W. A. Zhang, "Discussion of digital technologies and publicsculptures," Architecture \& Culture, vol. 145, no. 10, pp. 21-23, 2015.

[17] H.-C. Yang, "The logical structure of "artistry" in the creation of sculpture," Fine Arts Literature, vol. 33, no. 4, pp. 53-56, 2019.

[18] J.-Q. Cui, "Usion·Promotion-Development: design elements of the nowadays developing sculpture art region," Sculpture, vol. 5, pp. 66-67, 2015.

[19] D. Yan, "The application of 3D printing technology in the teaching of general technology," Experimental teaching and instruments, vol. 33, no. 1, pp. 37-44, 2016.

[20] L. Huang, "The utility of three-dimensional modeling technology in the display of silk road treasures," Electronics, vol. 10, pp. 163-165, 2020.

[21] W.-A. Luo, "Urban sculpture based on 3D scanning and 3D printing technology," Art panorama, vol. 96, no. 8, pp. 105$109,2020$.

[22] H. Wei, "Garment design and development based on 3D scanning technology," Textile Guide, vol. 103, no. 2, pp. 72-77, 2016.

[23] Y. Li, "Development of a 3D automatic measurement system for body dimensions," Journal of Northwest Textile Engineering College, vol. 15, no. 9, pp. 8-11, 2019.

[24] C. Liu, Data Processing and Feature Extraction for Laser 3D Remote Sensing, pp. 21-23, Science Publishing, Beijing, China, 2009.

[25] H. W. Zhou, Ground-based 3D Laser Scanning Point Cloud Data Processing and Model Construction, pp. 28-33, Kunming University of Technology, Kunming, China, 2011, Dissertation.

[26] Y. H. Ding, "Research on the alignment of ground-based 3D laser data," Journal of Surveying \& Mapping, vol. 30, no. 2, pp. 57-59, 2017.

[27] Y. Xu, "3D laser scanning technology," Mapping Information and Engineering, vol. 36, no. 4, pp. 5-6, 2017.

[28] L. Cheng, "Ground-based 3D laser scanning data alignment methods," Journal of Surveying \& Mapping, vol. 28, no. 12, pp. 80-85, 2017.

[29] X. Wang, Ground-based 3D Laser Scanning Modelling and its Application in Building Mapping, Dissertation, Central South University, Changsha, China, 2018.
[30] R. B. Rusu, Z. C. Marton, N. Blodow, M. Dolha, and M. Beetz, "Towards 3D Point cloud based object maps for household environments," Robotics and Autonomous Systems, vol. 56, no. 11, pp. 927-941, 2008.

[31] H. Luo, "Research on 3D model reconstruction technology based on terrestrial laser scanner,", Dissertation, East China University of Technology , 2016.

[32] C. Shi, "Discussion on mechanical engineering and automation," Architectural Engineering Technology and Design, vol. 20, pp. 38-42, 2017.

[33] Q. Mai, "Lab VIEW - based analysis and research of woodworking engraving machine spindle vibration," Modern Electronics Technique, vol. 37, no. 21, pp. 156-162, 2018.

[34] J. Wen, "Study on the application of handmade candles in mixed media decorative painting," Construction Materials \& Decoration, vol. 21, pp. 51-56, 2019. 